\title{
Narratividad y memoria. Hacia una ética de la responsabilidad
}

\author{
María Lucrecia Rovaletti ${ }^{1}$
}

Artículo original

\section{SUMMARY}

Prisoners of the Nazi concentration camps explained that the necessity to count all that horror stayed with them in life. In this moment, they were founding an "ethics of the testimony", that is to say, the salvation of the victims by means of their memory.

Indeed Ricoeur shows that "time becomes human time in the measurement in which it is articulated in a narrative way". In this sense, he points out that narrative plots constitute "the privileged means by which we form our confused, shapeless and, at limit, dumb, temporary experience". In spite of that, experience not always reaches to being object of a story. Sometimes, the traumatic experience prevents the individual from taking control of his/her personal history. There is a strong temptation to deny that this experience has taken place, or it is lived as if it happened to another person. In those "dark nights" of the soul, in those moments of extreme dispossession, «the question of "who am I" does not refer to the nullity, but it refers to the same nudity of the question» (Ricoeur).

For that reason, so that it is not an unbearable sequence of events, we narrated a story and we looked for its meaning. We do not do it to forgive or to forget, but to obtain "the privilege to judge". If the oblivion leads to a break from tradition, the truth however is not "a discovery that destroys the secret, but the disclosure that makes justice to it and allows to be passed on to the future generations" (Arendt).

Key words: Narrativity, memory, human rights, ethics, responsibility.

\section{RESUMEN}

Cuando los prisioneros de los campos de concentración nazi explicaban que aquello que los sostenía en la vida era la necesidad de contar todo aquel horror, estaban planteando una "ética del testimonio", es decir, la salvación de las víctimas mediante la actualidad de su recuerdo.

Precisamente Ricoeur muestra que "el tiempo deviene tiempo humano en la medida en que es articulado de manera narrativa", señalando de este modo que las tramas narrativas constituyen "el medio privilegiado por el cual reconfiguramos nuestra experiencia temporal confusa, informe, y al límite, muda". A pesar de ello, no siempre una experiencia alcanza a ser objeto de un relato, ya que la experiencia traumatizante a veces impide al sujeto apropiarse de su historia personal. Hay una fuerte tentación de negar que ésta haya tenido lugar, o es vivida como algo que le sucedió a otro distinto de uno. En esas "noches oscuras" del alma, en esos momentos de despojo extremo, "la pregunta de quién soy yo no reenvía a la nulidad sino a la nulidad misma de la pregunta" (Ricoeur).

Por eso, para que no sea una secuencia insoportable de acontecimientos, narramos una historia y buscamos su significado, no para condonar u olvidar, sino para obtener "el privilegio de juzgar". Si el olvido conduce a la quiebra de la tradición, la verdad en cambio no es "un descubrimiento que destruye el secreto, sino la revelación que le hace justicia y que le permite ser trasmitido a las futuras generaciones" (Arendt).

Palabras clave: Narratividad, memoria, derechos humanos, ética, responsabilidad.

Cuando "los prisioneros de los campos de concentración nazi explican que lo que les sostenía en la vida era la necesidad de contar todo aquel horror, lo que estaban planteando era la salvación de las víctimas mediante la actualidad de su recuerdo. No sólo querían recordarles como muertos, sino para ser salvados". ${ }^{1}$

\section{EL RELATO COMO UNA VICTORIA DEFINITIVA SOBRE LA AMENAZA DE NO-SENTIDO}

Al proponer Paul Ricoeur que "el tiempo deviene tiempo humano en la medida en que es articulado de manera narrativa", 2 está señalando que las tramas narrativas cons- tituyen "el medio privilegiado por el cual reconfiguramos nuestra experiencia temporal confusa, informe, y al límite, muda". ${ }^{2}$ En efecto, no se puede llegar al sí mismo sino por la mediación de nuestras propias historias, por la manera que las asumimos y por la forma que ellas toman forma, ya sea moderándose o volviéndose inextricables.

La comprensión que cada uno tiene de sí mismo es na-

Cátedra II de "Psicología, Ética y Derechos Humanos", Universidad de Buenos Aires. Consejo Nacional de Investigaciones Científicas y Técnicas (CONICET) Correspondencia: María Lucrecia Rovaletti. Juramento 1453, $4^{\circ}$ piso, Depto. 29, 1429, B.A. Capital Federal, Argentina. Teléfono/Fax: (+5411) 4783 - 9110. E-mail: mlrova@arnet.com.ar

Recibido: 1 de noviembre de 2012. Aceptado: 29 de mayo de 2013 
rrativa, porque no puede captarse fuera del tiempo. El relato transforma los acontecimientos humanos no necesariamente conexos entre sí en una estructura de trama y será la imaginación configuradora la que les otorgue sentido. ${ }^{3}$ Se articulan de este modo componentes disímiles como pueden ser circunstancias buscadas, encontradas, no deseadas...

A primera vista, todo sucede como si la intriga narrativa que realiza la sintesis de lo heterogéneo y la concordancia discordante, ${ }^{2}$ lograra una victoria definitiva sobre la amenaza de no-sentido contenida en las determinaciones negativas. En efecto, en toda trama aparecen distintos planos, unos que intervienen dinámicamente en su desarrollo y otros que permanecen estables pero también contribuyen a determinar el sentido de la historia.

Por eso es imposible imaginar una comunicación absolutamente transparente. Como bien lo mostrara Schleiermacher, los malentendidos forman parte del trabajo de comprensión. Más aún en toda historia, es imposible encontrar un fin objetivamente determinable ni un cierre definitivo ni un comienzo absoluto, ni se presta tampoco a ser subdividida en secuencias temporales meramente objetivas. ${ }^{4}$ En realidad, sólo describimos las múltiples maneras en que las historias pueden surgir o resurgir, algunas anunciándose desde hace tiempo, otras al contrario haciendo irrupción de manera brusca. Por eso comprender una historia, participar de una manera u otra en ella, significa abrirse a sus múltiples horizontes.

A pesar de ello, no siempre una experiencia alcanza a ser objeto de un relato, ya que la experiencia traumatizante a veces impide al sujeto apropiarse de su historia personal. Hay una fuerte tentación de negar que ésta haya tenido lugar, o es vivida como algo que le sucedió a otro distinto de uno. La clínica psicoterapéutica es rica en ejemplos de este tipo. La tarea del Yo consistirá en transformar esos documentos fragmentarios en una construcción histórica que aporte al autor y a sus interlocutores la sensación de una continuidad temporal. ${ }^{5}$ Sin embargo, una cohesión nunca podrá ser definitivamente comprendida ni conquistada. La identidad narrativa es por definición una identidad frágil, hecha de éxtasis y de envíos. ${ }^{6}$

\section{UNA IDENTIDAD HECHA ENTRE RESQUEBRAJADURAS}

La identidad narrativa es también ese ámbito donde se experimenta a veces hasta el extremo la propia falta de identidad. En esas "noches oscuras" del alma, en esos momentos de despojo extremo, "la pregunta de quién soy yo no reenvía a la nulidad sino a la nulidad misma de la pregunta".7 Analizando ciertas historias, uno comprende que "cada experiencia constituye un sinónimo de traumatismo demasiado violento para poder decírselo y con más razón refractario a la 'síntesis de lo heterogéneo' que lleva a cabo la intriga narrativa". 8
Ya no se puede seguir afirmando que existe una libertad ilimitada para relatar y constituir nuevas realidades. Si todo lo acontecido pudiera ser disuelto y sustituido por nuevas y nuevas versiones de sí mismo aunque fueran más coherentes y más liberadoras y benéficas para el analizado, ${ }^{9}$ el pasado carecería de efectividad.

Muy a menudo, "el sentido" de la propia identidad personal reside más bien en las resquebrajaduras, en ese salirse de una unidad social más amplia, en las pequeñas técnicas con las que se resiste a las presiones, apoyándose en la solidez y confianza de nuestro mundo. Pero en otros casos, las "inconsistencias" se refieren a la elaboración retroactiva de los efectos traumáticos de algunos acontecimientos "pasados" que sólo se actualizan posteriormente si se crean determinadas condiciones: es lo que Freud ${ }^{10}$ denomina Nachträglichkeit, ${ }^{*}$ retroactividad. Estas inconsistencias develan algo muy valioso: la presencia /ausencia de lo que es "fuera del tiempo", lo Zeitlos. En este sentido, Freud considera como algo "extemporáneo"** a estos efectos devastadores que abren heridas incurables y destruyen los recursos auto-regenerativos del psiquismo. Son como esos "fenómenos saturados", 11 son los traumas "acontecimientos inconclusos", 9 que impiden una recomposición del sentido y de la historia a causa del desgarro psíquico. Por ello acaban siendo una especie de no-hecho, de no-acontecido y son los que tal vez están más radicalmente "fuera del tiempo".

¿Cómo recoger y reunir estos pedazos de la "experiencia pasada" irrecuperables por la memoria, porque son inaceptables, ignominiosos hasta el punto tal de experimentar que de hecho no han acontecido? ¿Cómo aceptar y concebir que esa experiencia pueda ser vivida sólo ahora en una nueva condición, por primera vez? Estoy pensando en voz alta en los actos de violencia gratuita, como la tortura, el terrorismo:

"Las atrocidades sin embargo no son fáciles de suprimir. El esfuerzo por negar para olvidar es siempre infructuoso. Recordar y decir -y saber- la verdad es una condición para la recuperación del orden social y para la recuperación de las víctimas. Hablar la verdad-hablar de lo sucedido- o mantenerlo en secreto suelen ser tendencias contradictorias que se generan frente a las experiencias traumáticas. Si la verdad no se coloca en palabras, ella es hablada a través de los sintomas. Estos sintomas dan cuenta de lo indecible y al mismo tiempo lo mantienen encubierto en un lenguaje indescifrable. Estos síntomas hablan a través del cuerpo humano, son metáforas de la experiencia que continúa doliendo. O son metáforas sociales que es necesario situar en su contexto para poder entender su sentido y sus consecuencias". ${ }^{12}$

La Nachträglichkeit permite introducirnos en ese proceso del que no se es responsable por los efectos traumáticos

\footnotetext{
* Ha sido mérito de Jacques Lacan el haber llamado la atención sobre la importancia de este término.

** Lo extemporáneo del Inconsciente en Freud también se refiere a la insistencia indestructible de las emergencias pulsionales, a la resistencia cuasi indestructible de representaciones recalcadas, a las incidencias clínicas del Inconsciente.
} 
aparentemente diferidos. No se trata de una acción retardada ("deferred action", el "après coup", el a posteriori) sino el "trabajo de la memoria", de esa "memoria herida" (blessée), como dice Ricoeur. ${ }^{13 *}$ Pero en verdad, ¿se alcanza una verdadera reelaboración? ¿O es esa sombra que acompaña a la persona constantemente sin poder nunca integrarse? ¿No es más bien esa presencia de un Vacío, presencia de lo inenarrable? ¿Es posible entonces un proceso de constitución y reconstitución del sentido de esa experiencia? ¿Es posible que lo "fuera del tiempo" en todas sus figuras, sea reconocido y vivido como parte integrante e indisociable del flujo de las vivencias? Estas marcas afectivas, que pertenecen a título originario a las experiencias del persistir en la vida y que guardan la huella de un vacío y una negación, se perpetúan en la vida de los sobrevivientes.

En estas situaciones críticas hay siempre como una imposibilidad de testimoniar. Como muestra Agamben ${ }^{14}$ en Lo que queda de Auschwitz, la verdad de lo acontecido es muy difícil de ser contada y hasta se descree de ella. Allí reside también lo "inhumano" del horror, que se vuelve "humano" cuando es puesto en palabras, con todas las dificultades que ello acarrea, allí reside la valentía de hacerse cargo de lo que resta de lo humano después de la experiencia de lo inhumano de la que nadie está exento. Precisamente, "para el sobreviviente la muerte es en primer lugar 'no la desaparición ni el no ser ni la nada', sino una cierta experiencia de la 'sin-respuesta'"', señala Derrida' ${ }^{15}$ en su Adieu à Levinas.

El sobreviviente nunca sabe con certeza por qué subsistió y aunque busca de modo atormentado una repuesta, nunca la tendrá cabalmente: vivir ahora implica ese trabajo personal con esa la culpa prestada pues él vivió mientras que otros, la mayoría, murieron. Se siente como usurpando una existencia que no le pertenece del todo, una existencia que tal vez debía estar viviendo otro.**

En la clínica muchas veces nos vemos confrontados con lo incontable, lo incomunicable. ${ }^{* *}$ Si una única palabra debiera ser pronunciada al término de este descenso provocado por el horror, es la presencia de lo injustificable, inasumible, de lo in-analizable porque el analista se enfrenta aquí con mutilaciones del capital y del potencial psíquicos que no está en su poder "reparar" y que no tiene cómo develar al analizado. ${ }^{16-18}$ No por esto estaríamos reducidos a producir un simple rellenado, sino, por lo contrario, aceptar esa difícil tarea de habilitar a esos sujetos para reinvestir soportes, objetos, proyectos capaces de oponerse a la continuada acción de Tánatos, responsable de esas mutilaciones definitivas. Como el trabajo del duelo "en cuanto a la reconciliación con

\footnotetext{
* No se trata en este caso de quitar las "resistencias de lo reprimido" (Verdrängswiderstände), obstáculo principal para el trabajo de la interpretación sobre la vía de los recuerdos traumáticos. Aquí, bajo la "compulsión a la repetición" hay una tendencia de pasaje al acto (Agieren), que Freud designara como "sustitución del recuerdo": el paciente reproduce el hecho olvidado bajo la forma de acción. Rememoración, repetición y preelaboración constituirían tres comportamientos para una reconciliación (Versöhnung) del enfermo con lo reprimido.
}

la pérdida misma, permanece para siempre como una tarea inacabada", por ello "esta paciencia ante sí mismo reviste los rasgos de una virtud". ${ }^{13}$ Ricoeur reconoce que la unidad de la trama del relato choca sin cesar con todos estos acontecimientos contingentes que ponen en cuestión las esperas creadas por el curso anterior de la vida. Hay una desoladora contingencia de las acciones humanas, dada la irreversibilidad e irrevocabilidad de las acciones pasadas de las que no podemos saber cómo y cuándo se originaron, como de la impredictibilidad de las acciones futuras. ${ }^{19}$

Las narrativas convencionales, esas bellas y apaciguantes historias en las que el sentido ha sido tejido cuidadosamente, no alcanzan a dar cuenta de la temporalidad humana. En efecto, lo extemporáneo se verá irrumpir inevitablemente porque es justamente desde esas irrupciones y en esas irrupciones que el tiempo se temporaliza. Siempre recomienza pero jamás desde el comienzo, o mejor sin saber definitivamente nunca dónde está el comienzo, el medio y el fin de las narrativas. Cada "momento" estará siempre remitiendo a y siendo atraído por otros "momentos" en la constitución de una historia fracturada y sobredeterminada por un "antes" y un "después". Con esto no se deja de lado la función constitutiva del relato, sino que se busca establecer cuáles son las condiciones y medios para que lo extemporáneo pueda ser de alguna manera acogido, en algunos casos configurado, y en otro dejado en libertad para una actividad imprevisible pero enriquecedora. Para que no sea una secuencia insoportable de acontecimientos, narramos una historia y buscamos su significado, no para condonar u olvidar, sino para obtener "el privilegio de juzgar", plantea Hanna Arendt. ${ }^{20} \mathrm{Si}$ el olvido conduce a la quiebra de la tradición, la verdad en cambio no es "un descubrimiento que destruye el secreto, sino la revelación que le hace justicia"21 y que le permite ser trasmitido a las futuras generaciones.

\section{EL DEBER DE MEMORIA COMO DEBER DE HACER JUSTICIA}

Aunque "el dominio totalitario" busque siempre formar "bolsones de olvido" en cuyo interior desaparecerían "todos los hechos, buenos y malos", ello está destinado al fracaso, pues "hay en el mundo demasiada gente para que el olvido sea posible. Siempre quedará un hombre vivo para contar la historia", ${ }^{21}$ siempre la verdad se filtrará por los resquicios que deja el poder supuestamente omnímodo. Recordar para no repetir, señalaba Adorno. ${ }^{22}$

\footnotetext{
** También la culpa puede ser experimentada por los que nunca pasaron esas situaciones de tortura o terrorismo, como lo señala Karl Jaspers en El problema de la culpa, Barcelona, Paidós, 1999.

*** Es también la imposibilidad de garantizar alguna correspondencia entre la representación y la cosa representada; es la dificultad de teorizar un "objeto" necesariamente esquivo y nada objetivable como el "inconsciente", es la posible correlación entre "interpretaciones" o "reconstrucciones" y la "historia factual".
} 
"¿Pero qué significa, entonces hacer justicia con las víctimas? ¿Qué significa hacer justicia con esas injusticias de las que se hace cargo la memoria? ¿Cómo hacer presente a esos ausentes que no están, no porque se hayan ido, sino porque han sido 'idos', han sido desaparecidos?"23

Hacer justicia frente al daño personal -muerte, secuestro, tortura, inamenaza- es imposible, sólo cabe una modesta pero fundamental justicia como es la plena conciencia de "lo irreparable". Frente al daño político -el asesinado y desaparecido es negado en su derecho a la ciudadanía- la única salida es ubicarlo nuevamente en ella. Reparar o hacer justicia por el daño social -cuando la sociedad ha sido fracturada y empobrecida por la violencia-, es recuperar a las víctimas y victimarios. ${ }^{23}$

Precisamente, la justicia que sólo es memoria no basta, hay que hablar de la reconciliación. * Pero para ello, es preciso que el victimario reconozca su acción dañina y entienda lo que ha hecho. El perdón sólo puede darlo la víctima, y nadie puede exigirle ello, por eso es gratuito, que no es lo mismo que gratis.

Somos responsables históricamente, de lo que hemos hecho y de los que dejamos de hacer. Cuando Primo Levi ${ }^{24}$ se preguntaba qué podemos hacer nosotros, respondía que si desaparecieran los testigos, no habría memoria, ni por tanto la posibilidad de la justicia. Por ello la necesidad de seguir recordando al testigo, manteniendo la conciencia de una injusticia que pide justicia y hasta transformarnos a nosotros mismos en "testigos".

De este modo, la memoria, esa lucha contra el olvido, permite mantener vivos y vigentes los derechos que una vez les fueron negados a las víctimas. "El deber de memoria, es el deber de hacer justicia, por el recuerdo de un otro que sí", ${ }^{13}$ y el olvido implica la sanción de la injusticia. Como señalara Todorov, ${ }^{25}$ una memoria genuina deviene siempre ejemplar en la medida que asume la responsabilidad no sólo de preservar el pasado sino sobre todo el compromiso de evitar la reiteración del horror acaecido en el presente. Desde la noción de "responsabilidades retrospectivas", se es responsable por los resultados de ciertas conductas, sobre todo aquellas producidas de modo intencional, ya sea por acción u omisión; desde las "responsabilidades prospectivas" hay una responsabilidad a priori ante los posibles acontecimientos que se deben atender o cuidar de modo obligatorio.

Precisamente, el sufrimiento de un pueblo no puede caer en el olvido porque la narración permite sobrellevar y sobreponerse al mismo. En este sentido, las narraciones deberán pasar de la vida individual a ser patrimonio ético y

\footnotetext{
* Quede para otro trabajo el tema de la "reconciliación", tal como se ha venido realizando entre la comunidad judía y la alemana, entre víctimas de la ETA, entre serbios (cristianos ortodoxos), croatas (católicos) y bosnios (musulmanes) del ex estado multiétnico Bosnia-Herzegovina que como consecuencia del conflicto que duró mas de tres años produjo cerca de 100000 víctimas entre civiles y militares y 1,8 millones de desplazados. Algo similar ocurre entre la población en Chile, en la República del Salvador ....
}

cultural de un pueblo. Será la memoria, esa justicia anamnética como señala Reyes Mate ${ }^{1}$ la que nos devuelva la mirada del oprimido, como proceso abierto de salvación de historias olvidadas y afirme desde los inicios la responsabilidad como primer paso ético que me induce a cargar con su suerte.

\section{DAÑO AL PROYECTO DE VIDA, REPARACIÓN Y EXCULPACIÓN}

Si culparse por algo ante alguien es in-culparse, "la reparación de la culpa sólo puede sobrevenir por la exculpación", es decir por la disculpa que la víctima nos concede. "Quien en todo caso perdona es el otro, el mismo que antes nos hacía culpable", afirma Castilla del Pino. ${ }^{26}$

Uno se culpa del daño realizado, pero no se trata primariamente de un menoscabo por los bienes vitales y económicos perdidos; va más allá del daño físico y moral, es el daño a la persona misma, es decir a su propio proyecto de vida* y todo lo que afecte al mismo. Su radicalidad lesiona nada menos que el derecho de la persona a elegir su propio destino, es decir la libertad del sujeto a optar por un modo de realizarse. De allí que constituya una pérdida o un grave menoscabo de sus posibilidades personales, en forma irreparable o muy difícilmente reparable (Fernández Sessarego ${ }^{27}$ y que sólo puede alcanzar una reparación simbólica al incluir las garantías de no repetición, de un "nunca más".

En este sentido, se requiere no culpabilizar a la víctima e interpretar las manifestaciones psicológicas de la persona afectada como respuesta a una situación traumática, y no suponer que una presunta psicopatología subyacente llevaría a la víctima a generar el mismo hecho desestabilizante. A diferencia del trastorno por estrés postraumático que se refiere a un hecho o acontecimiento disruptivo, las situaciones padecidas por las víctimas a causa del terrorismo de Estado se prolongan en el tiempo y mantiene muchos episodios puntuales disruptivos.

Así, por ejemplo, la apropiación de niños durante la dictadura argentina no constituye sólo un "episodio traumático", sino un proceso que abarca una buena parte de sus vidas. Para los familiares de desaparecidos o los familiares que buscan a estos niños hoy adultos, el hecho delictivo no cesa de ocurrir, por eso se consideran delitos imprescriptibles. Del mismo modo, también lo son para la salud mental, dado que el hecho traumático no cesa de ocurrir.

Finalmente, es fundamental a los fines reparatorios en estas situaciones traumáticas, el poder contextualizar estos

\footnotetext{
* El trastorno por estrés postraumático no da cuenta de las múltiples manifestaciones sintomatológicas del trauma, ni de las profundas y persistentes alteraciones en la personalidad que éste provoca, ni la permanencia y continuidad en el tiempo. Y una limitación de este concepto es su falta de consideración por el sentido que los hechos traumáticos tienen para la víctima. En los crímenes de lesa humanidad, se afecta intensa y directamente la dignidad de la persona y su proyecto de vida a lo largo del tiempo.
} 
hechos mas allá del ámbito individual. ${ }^{28-34}$ En este sentido, cobra importancia el efecto reparatorio simbólico de todas las políticas del Estado al respeto. ${ }^{35-38}$ Como planteara el Vicario de la Solidaridad de Chile, ${ }^{12}$

"... la verdad, la justicia y la reparación del daño causado a los afectados, y también a la sociedad son elementos fundamentales para lograr verdadera reconciliación. La nación entera debe comprometerse en el futuro proceso de democratización y construcción de una sociedad solidaria, el respeto irrestricto de los derechos humanos individuales y civiles" para que "sean elementos constitutivos de la institucionalidad" (Diario La Tercera, Chile, 25-11-1989).*

\section{REFERENCIAS}

1. Reyes Mate M. "En torno a una justicia anamnética". En: Mardones J, Reyes Mate M (eds.). La ética ante las víctimas. Barcelona: Anthropos; 2003; pp. 100-125.

2. Ricoeur P. Temps et Récit; L'intrigue et le récit historique. París: Du Seuil; 1983 (TR,I).

3. Ricoeur P. Temps et Récit; La configuration dans le récit de fiction. París: vol. II ; Du Seuil; 1984 (TR, II).

4. Rovaletti ML. Narration and temporality. Towards an ethics of memory. En: Lorenzo Calvi (org.) Comprendre, $\mathrm{N}^{\circ}$ 16-17-18, pp.346-354, 2008; De la hermenéutica del relato a la hermenéutica de la recepción. Acta Fenomenológica Latinoamericano, vol. I, (Órgano del Círculo Latinoamericano de Fenomenología, Clafen), Lima, Pontificia Universidad Católica del Perú, 2003, pp. 347-357; La Memoria Histórica como tarea.En M. L. Rovaletti y S.M. De Filpo, (Ed.) Espacios de la Memoria. Una experiencia de vida y de ciudadanía. DVD realizado en el Espacio para la Memoria. Cátedra II de "Psicología, Ética y DDHH" y Secretaría de Extensión, Cultura y Bienestar Universitario, Facultad de Psicología, Universidad de Buenos Aires, 2010.

5. Aulagnier Piera. El aprendiz de historiador y el maestro brujo. Buenos Aires: Amorrortu; 1992.

6. Ricoeur P. Temps et Récit; Le temps raconté. París: vol. III; Du Seuil; 1985 (TR, III).

7. Ricoeur P. Soî-meme comme un autre. París: Du Seuil; 1990.

8. Greisch J. Empêtrement et intrigue. Une phénoménologie pure de la narrativité est-elle concevable? París: Études Phénoménologiques, $\mathbf{N}^{\circ}$ 11; 1990; pp. 41-83.

9. Figueiredo LC. Temporalidad y narratividad en los procesos de subjetivación de la clínica psicoanalítica. En: Rovaletti, ML (ed.). Temporalidad. El problema del tiempo en el pensamiento actual. Buenos Aires, Argentina: Lugar Editorial; 1998; pp. 271-282.

10. Freud S. Obras completas. Madrid: Ed. Biblioteca Nueva; 1973.

11. Marion J-L. Etant donné; Essai d'une phénomènologie de la donation. París: PUF; 1997.

12. Lira E (ed.). Reparación, derechos humanos y salud mental. Santiago de Chile: Ediciones ChileAmerica CESOC; 1996.

13. Ricoeur P. La memoire, l'histoire, l'oubli. París: Seuil; 2000.

14. Agamben G. Lo que queda de Auschwitz. El archivo y el testigo. Valencia: Homo Sacer III; Pre-textos; 2000.

15. Derrida J. Adieu à Levinas. Disponible el 17-08-2011, en: http://www. jacquesderrida.com.ar/textos/adieu.htm
16. Bollas $\mathrm{Ch}$, Botella $\mathrm{S}$. Le statut métaphychologique de la perception et l'irrepresentable. París: LVI; Revue Française de Psychanalise; 1992; pp. 23-41.

17. Hochmann J. Intersubjectivité, empathie et narration dans le procesus psychothérapique. En: AAVV- Forum Diderot, Qu'est-ce que guérit dans la psychothérapie? París: PUF; 2001; pp. 11-34.

18. Naciones Unidas: Protocolo de Estambul. Manual para la investigación y documentación eficaces de la tortura y otros tratos o penas crueles, inhumanos o degradantes. Ginebra, 1991. Disponible el 20-12-2012, en www.unhchr.ch

19. Arendt H. De la historia a la acción. Barcelona: Paidós; 1997.

20. Arendt, H.: Hombres en tiempos de oscuridad, Barcelona, Gedisa, 1992.

21. Arendt H. Eichmnan en Jerusalem. Buenos Aires: Paidós; 1999.

22. Adorno ThW. Minima moralia. Reflexiones desde la vida dañada. Madrid: Taurus; 1982.

23. Reyes Mate M. Justicia y memoria, la significación política de las víctimas. Nuestra memoria. Buenos Aires: Año XV, $\mathrm{N}^{\circ} 32$, agosto 2009; pp. 17-26.

24. Primo Levi. Si esto es un hombre. Barcelona: El Aleph; 2003.

25. Todorov T. Memoria del mal, tentación del bien. Indagación sobre el siglo XX. Barcelona: Península; 2002.

26. Castilla del Pino C. La culpa. Madrid: Alianza; 1981.

27. Fernández Sessarego C. El daño al proyecto de vida en la jurisprudencia de la Corte Interamericana de Derechos Humanos. Lima: Derecho PUCP, $\mathbf{N}^{\circ}$ 56; diciembre del 2003.

28. Cerutti M. La memoria de las víctimas. Testimonios para una reflexión ética. En: Mardones J, Reyes Mate M (eds.). 2003, pp. 243-267.

29. Kovalskys J, Lira E. Trauma social y reparación. En: Lira E (ed.). 1996, pp. 21-57.

30. Lira E, Gómez E. Reparación y salud mental: Programa PRAIS. En: Lira E (ed.). 1996; pp. 123-146.

31. Lira E. Programas de salud mental y derechos humanos durante la dictadura. En: Lira E (ed.). 1996; pp. 81-106.

32. Lira E. Violaciones de los derechos humanos y psicoterapia. En: Lira E (ed.). 1996; pp. 107-122.

33. Morales G, Lira E. Dinámicas de riesgo y cuidados de equipos que trabajan con situaciones de violencia. En: Lira E (ed.). 1996; pp. 165-182.

34. Taffala M. Recordar para no repetir: el nuevo imperativo categórico de T.W. Adorno. En: Mardones J, Reyes Mate M (eds.). 2003; pp. 126-154.

35. Sucasas A. Interpelación a la víctima y exigencia de justicia. En: Mardones J, Reyes Mate M (eds.). 2003; pp. 76-99.

36. Valladolid Bueno T. Los derechos de las víctimas. En: Mardones J, Reyes Mate M (eds.). 2003; pp. 155-173.

37. Bárcena F, Mèlich JC. La mirada excéntrica. Una educación desde la mirada de la víctima. En: Mardones J, Reyes Mate M (eds.). 2003; pp. 195-218.

38. Cuadernos de la Memoria $\mathbf{N}^{\circ}$ 1. Leyes. Principales instrumentos legales sobre derechos humanos y memorias. Buenos Aires: Espacio de la Memoria; 2009.

Artículo sin conflicto de intereses

* Citado en p. 63, en Lira (comp.), op.cit. ref. 12. 